\title{
Distinguishing negative polarity from concord in Korean
}

\author{
Jungmin Kang (jung-min.kang@uconn.edu) \& Lyn Shan Tieu (lyn.tieu@gmail.com) \\ University of Connecticut
}

\section{Introduction}

A common assumption about negation-sensitive elements such as amwu-N-to in Korean is that they are negative polarity items (NPIs), with a meaning similar to the English any (Sells \& Kim, 2006; Kim, 1999; Lee, 1995 among many others). But as any-type NPIs, they have some rather idiosyncratic properties. For example, they are only licensed by negation; typical NPI licensers (e.g., polar questions, antecedents of conditionals) fail. These items also appear to exhibit wide scope with respect to negation. Moreover, they require clausemate negation. One might think to characterize these items instead as runof-the-mill negative concord items (NCIs). In this respect, it is insightful to consider the following differences that have been noted between NPIs and NCIs:
a. Ability to be modified by expressions like almost
b. Ability to be used as an elliptical answer
No Yes
c. Ability to appear in non-negative contexts
No Yes
d. Ability to be licensed by a higher clause negation
Yes No
e. Participation in indeterminate system ${ }^{1}$

Yes No
No Yes

NPI NCI

(Watanabe 2004; Sano et al., 2008, among others)

Given the NPI/NCI distinctions in (1), amwu-N-to would be better viewed as a run-of-the-mill NCI rather than as an idiosyncratic NPI. In this extended abstract, we present data pertaining to a similar negation-sensitive element, etten-N-to, which falls in line with neither the NPI nor the NCI column in (1). Given the distribution of amwu-N-to and etten-N-to, we suggest that there are in fact two kinds of NCIs in Korean, with different morphosyntactic properties.

\section{Data}

We take as the object of study apparent quantificational elements such as etten. Etten- $\mathrm{N}$ is used as a whindefinite in wh-questions, as an existential quantifier in declaratives, and additionally with the (evenlike) focus particle -to constitutes a negation-sensitive element (etten-N-to). Amwu-N-to is likewise a negation-sensitive element, but amwu typically is not used as an existential quantifier or $w h$-indefinite.

(2) John-i *amwu/etten-chayk-ul ilk-ess-ni?

John-NOM amwu/etten-book-ACC read-PERF-Q

'Which book did John read?'

As negation-sensitive elements, both etten-N-to and amwu-N-to can appear either in subject or object position, in declaratives or interrogatives, but always require clausemate negation to be licensed:

\footnotetext{
${ }^{1}$ We follow Gill et al.'s (2006) definition of indeterminate-based quantification, according to which an indeterminate pronoun associates with an operator-like element to form a quantificational expression.
} 
(3)a. John-un \{etten/amwu $\}$-kes-to sa-ci anh-ass-ta John-TOP etten/amwu-thing-TO buy-CI NEG-PERF-DECL

'John didn't buy anything/John bought nothing'

b. *John-un \{etten/amwu\}-kes-to sa-ass-ta

John-TOP etten/amwu-thing-TO buy-PERF-DECL

(4)a. \{etten-salam/amwu\}-to o-ci anh-ass-ta.

etten-person/amwu-TO come-CI NEG-PERF-DECL

'No one came'

b. * $\{$ etten-salam/amwu $\}$-to wa-ss-ta

etten-person/amwu-TO come-PERF-DECL

(5) *Bill-un John-i \{etten/amwu\}-kes-to sa-ss-ta-ko malha-ci anh-ass-ta Bill-TOP John-NOM etten/amwu-thing-TO buy-PERF-DECL-COMP say-CI NEG-PERF-DECL

'Bill didn't say that John bought anything'

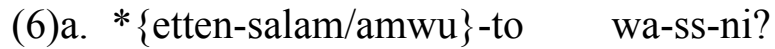

etten-person/amwu-to come-PERF-Q

b. \{etten-salam/amwu $\}$-to o-ci anh-ass-ni?

etten-person/amwu-TO come-CI NEG-PERF-Q

'Did anybody come?'

There are however a number of differences in the behaviour of etten-N-to and amwu-N-to: (i) amwu-Nto but not etten-N-to can form (negative) fragment answers (7); (ii) amwu-N-to but not etten-N-to can be modified by keuy 'almost' (8) (Sells \& Kim, 2006; Lee, 1995; Lee, 1996; Lee, 2001); (iii) lexically negative predicates, in which negation is generally restricted to the predicate, license amwu-N-to (Chung \& Park, 1998), but appears to be degraded with etten (9).

(7)
Q: mwues-ul po-ass-ni?
what-ACC see-PERF-Q
'What did you see?'

(8)

(9) John-un $\left\{?^{*}\right.$ etten/amwu $\}$-kes-to molu-n-ta

John-TOP etten/amwu-thing-TO not.know-MOOD-DECL

'John doesn't know anything'

(8) John-un keuy $\{*$ etten/amwu $\}$-kes-to mek-ci anh-ass-ta

'John ate almost nothing'
A: *etten/amwu-kes-to etten/amwu-thing-TO
'Nothing' John-TOP almost etten/amwu-thing-TO eat-CI neg-PERF-DECL

Adding amwu-N-to and etten-N-to to the schema in (1) yields the following: 
(10)
a. Ability to be modified by expressions like almost
b. Ability to be used as an elliptical answer
c. Ability to appear in non-negative contexts
d. Ability to be licensed by a higher clause negation
e. Participation in indeterminate system

NPI NCI amwu-N-to etten-N-to

$\begin{array}{llll}\text { No } & \text { Yes } & \text { Yes } & \text { No } \\ \text { No } & \text { Yes } & \text { Yes } & \text { No } \\ \text { Yes } & \text { No } & \text { No } & \text { No } \\ \text { Yes } & \text { No } & \text { No } & \text { No } \\ \text { No } & \text { Yes } & \text { No } & \text { Yes }\end{array}$

We see that (i) negation-sensitive elements in Korean do not behave uniformly, and (ii) neither amwu nor etten pattern perfectly with typical NPIs or NCIs.

\section{Proposal}

We propose that there are two types of NCIs in Korean, modeled off of either amwu or etten. ${ }^{2}$ We derive their diverging properties by appealing to their particular morphosyntactic features. Assume that Agree is driven by the need to value features (cf. Pesetsky \& Torrego, 2007; Bošković, 2009b, 2011; Wurmbrand, 2011, to appear; Smith, 2012). Amwu-type NCIs can be seen as bearing an unvalued, interpretable Neg feature [ $i \mathrm{Neg}:[]$, while etten-type NCIs bear an unvalued, uninterpretable Neg feature $[u \mathrm{Neg}:[]$. The unvalued Neg feature on these NCIs results in their requirement to be 'licensed' by negation. Assume further that a negative head in Korean bears either a valued interpretable Neg feature [ $i \mathrm{Neg}: v a l]$ or a valued uninterpretable Neg feature $[u \mathrm{Neg}: v a l]{ }^{3}$ The differences between ettentype and $a m w u$-type NCIs now fall out naturally.

Consider first $w h$-uses (2). Etten differs from amwu in that it does not bear an interpretable [iNeg] feature; it is thus not semantically negative and unlike $a m w u$, can be used as a $w h$-indefinite. Note that unlike amwu-, etten- also appears to trigger an existential presupposition; it is odd when uttered out of the blue.

Next, consider negative fragment answers. We adopt Bošković (2009a)'s explanation of parallel facts in Serbo-Croatian. Ellipsis requires that what is elided be semantically identical to the antecedent (Merchant, 2001); in (7), the antecedent to the elided phrase is not negative, and therefore what is elided cannot be semantically negative. But since the answer contains an NCI, it must also contain a negative head to license the NCI. The only way to satisfy both requirements is for the negative head to bear an uninterpretable $[\mathrm{uNeg}]$ feature. Given that etten-N-to bears $[u \mathrm{Neg}$ :_], if what is elided contains a negative head with [ $u \mathrm{Neg}$ : $v a l]$, there is no way to derive a negative answer meaning. In contrast, we derive a negative answer with $a m w u$-N-to, whose interpretable [iNeg:__ feature gets valued by [uNeg: val] of the negative head.

Next, consider the almost-modification facts in (8). If amwu-N-to, with its [iNeg] feature and obligatory outscoping of negation, is actually a negative universal quantifier, we expect it to be modifiable by almost. In contrast, the existential etten-N-to ought not to be modifiable by almost.

As for the lexical negation facts in (9), we assume that lexical negation in Korean projects a NegP (cf. Chung 2007). Like negative heads, lexical negation can bear either a valued interpretable Neg feature [ $i \mathrm{Neg}: v a l]$ or a valued uninterpretable Neg feature [ $u \mathrm{Neg}: v a l]$. At this point, we must stipulate that only the lexical negation with [ $u \mathrm{Neg}$ : val] can co-occur with NCIs. If this is the case, then only $a m w u$-N-to can co-occur with lexical negation, since only it has an [iNeg] feature.

\footnotetext{
${ }^{2}$ See Bošković (2009a) for arguments that Serbo-Croatian also exhibits two kinds of NCIs $(i-/ n i$-NCIs).

${ }^{3}$ See Bošković (2009a) for a similar proposal for negation in Serbo-Croatian.
} 


\section{Conclusion}

We have examined a range of data that forces a revision in the classificatory system of negationsensitive elements in Korean. Given previous depictions of the NPI/NCI distinction, we have suggested that amwu-N-to is better analyzed as an NCI. But given various distinctions between amwu-N-to and etten-N-to, we must expand our classification of NCIs in Korean. Future work includes identifying the precise semantic differences between etten-and amwu-type quantificational elements.

\section{References}

Bošković, Ž. 2009a. Licensing Negative Constituents and Negative Concord. In Proceedings of the North East Linguistic Society 38, 125-139. GLSA, University of Massachusetts, Amherst.

Bošković, Ž. 2009b. Unifying First and Last Conjunct Agreement. Natural Language and Linguistic Theory 27.3:455-496.

Bošković, Ž. 2011. On unvalued uninterpretable features. In Proceedings of the North Eastern Linguistics Society Annual Meeting 39. Amherst: University of Massachusetts, GLSA.

Chung, I. 2007. Suppletive negation in Korean and Distributed Morphology. Lingua 117(1):95-148.

Chung, D. \& H. Park. 1998. NPIs outside of negation scope. In Japanese/Korean Linguistics, Vol. 6:415-435. Stanford: CSLI, Stanford Linguistics Association.

Gill, K., S. Harlow, \& G. Tsoulas. 2006. Disjunction and indeterminate-based quantification in Korean. Ms., University of York.

Kim, K. 1999. A paradox in Korean NPI licensing. Studies in Generative Grammar 9:403-428.

Lee, C. 1995. A unified account of polarity phenomena. In Proceedings of the 10 th Pacific Asia Conference on Language, Information and Computation, 281-291.

Lee, H. 1996. Two types of polarity sensitive (PS) "ANY". Language Research 32:237-266.

Lee, H. 2001. The morphology-based semantics of "any" in English and Korean. Enehak 31:127-158.

Merchant, J. 2001. The Syntax of Silence. Oxford: Oxford University Press.

Pesetsky, D, \& E. Torrego. 2007. The syntax of valuation and the interpretability of features. In Phrasal and clausal architecture, ed. by S. Karimi, V. Samiian, \& W. Wilkins, 262-294. Amsterdam: John Benjamins.

Sano, T., H. Shimada, \& T. Kato. 2009. Negative concord vs. negative polarity and the acquisition of Japanese. In Proceedings of the 3rd Conference on Generative Approaches to Language Acquisition North America, 232-240.

Sells, P. \& S. Kim. 2006. Korean NPIs scope over negation. Language Research 42(2):275-297.

Smith, P. 2012. Collective (dis)Agreement: On a 3/4 pattern of British English Collective NPs. Talk given at ConSOLE XX, Leipzig.

Watanabe, A. 2004. The Genesis of Negative Concord: Syntax and Morphology of Negative Doubling. Linguistic Inquiry 35-4: 559-612.

Wurmbrand, S. To appear. The syntax of valuation in auxiliary-participle constructions. In Coyote Working Papers: Proceedings of the 29th West Coast Conference on Formal Linguistics (WCCFL 29). University of Arizona: Tucson. 